\title{
Welfare and Work Sanctions: Examining Discretion on the Front Lines
}

\author{
Vicki Lens \\ Columbia University
}

\begin{abstract}
Sanctions are a key tool for enforcing welfare reform's work requirements, but little attention has been paid to how laws, administrative procedures, judicial decisions, and worker discretion interact in the application of sanctions on the front lines. This study analyzes administrative fair hearing decisions and in-depth interviews with sanctioned recipients. The findings suggest that workers interpret and apply sanction rules narrowly, failing to distinguish procedural violations from substantive ones. It also finds that workers are skeptical about claims of good cause exceptions from work rule violations, are strict in the application of the rules governing such exceptions, and overlook rules requiring them to show that a client's action (or inaction) was willful before imposing sanctions. Sanctions are applied across various groups of clients, including those engaged in ongoing work activities, as well as those who are disadvantaged and less willing to work.
\end{abstract}

Declining caseloads and increased work among recipients have led many scholars and policy makers to herald welfare reform as a success (Rector and Youssef 1999; O'Neill and Hill 2003; U.S. Senate 2003; Haskins 2006). This success frequently is attributed to policies that propel recipients quickly and forcibly into the labor market (Rector and Youssef 1999; O'Neill and Hill 2003; U.S. Senate 2003; Haskins 2006). In welfare reform, employment services approaches that emphasize training and education are replaced by aggressive interventions that require recipients to seek and accept any job or lose their benefits. Sanctions, which are financial penalties for violating welfare's rules, provide welfare caseworkers with a powerful tool for ensuring compliance. Scholars consider the sanctions along with more positive incentives, such as supports and work-related services, to be responsible for welfare reform's perceived success (Rector and Youssef 1999; Mead 2001).

Social Service Review (June 2008).

(C) 2008 by The University of Chicago. All rights reserved.

0037-7961/2008/8202-0002\$10.00 
However, little attention has been paid to how sanctions are applied on the front lines (Pavetti, Derr, and Hesketh 2003). Rather, research tends to focus on sanction rates, characteristics of sanctioned families, and the long-term effect of sanctions on families' well-being (Born, Caudill, and Cordero 1999; Fein and Lee 1999; Edelhoch, Liu, and Martin 2000; Koralek 2000; Westra and Routley 2000; Mancuso and Lindler 2001; Polit, London, and Martinez 2001; Cherlin et al. 2002; Kalil, Seefeldt, and Wang 2002; Hasenfeld, Ghose, and Larson 2004; Pavetti et al. 2004; Wu et al. 2006). For information on sanction policies and procedures, the few implementation studies rely largely on data from administrators, from frontline workers, and to lesser extent, from clients (Fraker et al. 1997; U.S. Department of Health and Human Services 1999; Pavetti et al. 2004). These studies do not fully capture the complex mix of rules, administrative procedures, and worker discretion involved in the application of sanctions.

The current study uses a triangulated research design. The design combines a content analysis of administrative fair hearing decisions on welfare sanctions from a suburban county located in New York with indepth qualitative interviews of sanctioned recipients, as well as with a review of the laws, regulations, judicial decisions, and administrative directives involving sanctions. Laws and administrative procedures provide structure and guidance for sanction decisions, describing what should happen during the sanctioning process. Fair hearing decisions, which are the product of administrative proceedings initiated by clients to challenge negative agency actions, provide a detailed and individualized administrative account of what occurs from the perspectives of both recipients and workers. Recipient interviews provide a less structured and less bureaucratically confined version of similar events. Together, these data shed light on how laws, administrative procedures, and workers' discretion interact in the application of sanctions.

\section{Background and Context}

The Personal Responsibility and Work Opportunity Reconciliation Act of 1996 (U.S. Public Law 104-193) requires the use of sanctions to address noncompliance with a number of welfare rules, but states have the option of imposing partial or full-family sanctions. Under a partial sanction regime, only a portion of the recipient's welfare grant is reduced when an adult member violates a work rule. Under a full-family sanction regime, the entire family loses its grant for such a violation. The majority of states (36) impose some form of full-family sanction, eliminating the welfare grant to the entire family, including children, either immediately or gradually. Fourteen states, including the two states with the largest populations of welfare recipients (California and New 
York), impose partial sanctions, which eliminate only the noncompliant adult's portion of the grant (Pavetti et al. 2003).

One purpose of sanctions is to encourage compliance with work rules. They are part of what Lawrence Mead $(1997,24)$ calls the "help and hassle" prescription for influencing recipients' work behaviors. By requiring recipients to engage in work activities, under threat of financial penalties if they do not, self-sufficiency is encouraged rather than dependency. Although welfare reform legitimizes hassle by requiring sanctions, the welfare system has also been reconfigured to help recipients to become self-sufficient. Staff responsibilities have been restructured and new relationships forged with outside service providers, such as workforce boards or labor departments, which are knowledgeable about the labor market (Martinson and Holcomb 2002). Local service offices still make basic eligibility determinations, but they also are encouraged to function more like job centers than like welfare agencies (Lurie 2006). Welfare reform emphasizes (and provides funding for) support services, such as child care and transportation. Many programs use the social work or case management model, which emphasizes flexibility and personalized services (Segal, Gerdes, and Steiner 2004).

Under such a model, one might reasonably presume that sanctions are applied flexibly and that workers consider the client's work behavior in making individualized and holistic evaluations. Supports and sanctions also presumably are balanced; the latter imposed only on clients unwilling to participate in work activities. Both before and since welfare reform, however, scholars have noted that welfare bureaucracies are often more apt to process paper than to process people. Thomas Kane and Mary Jo Bane $(1994,7)$ coin the term "eligibility-compliance culture" to describe bureaucracies in which workers focus on procedural rules and paperwork rather than on the helping relationship. Before welfare reform, program efforts to encourage work demonstrated that eligibility-compliance cultures are hard to uproot. In her study of the Job Opportunities and Basic Skills program (JOBS), Evelyn Brodkin (1997) finds that agency-performance incentives, including work quotas and federal reimbursement rates, constrain workers' choices. These incentives also encourage workers to ignore clients' preferences and needs. Similarly, Yeheskel Hasenfeld (2000) finds that JOBS workers institutionalize moral assumptions and stereotypes in their daily interactions with clients, choosing to treat clients with suspicion and distrust. He also notes that workers use "highly routinized and bureaucratized" service technologies to assess clients and monitor compliance with work rules (Hasenfeld 2000, 333).

The Temporary Assistance for Needy Families program (TANF) ushered in sweeping organizational and other reforms, but the resistance to change persisted, especially among frontline workers (Meyers, Glaser, 
and MacDonald 1998; Meyers and Dillon 1999; Sandfort 2000; Lurie and Riccucci 2003; Riccucci et al. 2004). In a study that included 11 welfare sites in four states, welfare workers are found to resist organizational reforms that emphasize work-based goals, instead focusing on traditional eligibly determinations (Riccucci et al. 2004; see also Lurie and Riccucci 2003). Workers report that the implementation of TANF changed their jobs little, except for increasing their paperwork. These findings suggest that work-based goals do not replace but are grafted onto preexisting eligibility-compliance cultures. Similarly, Jodi Sandfort (2000) finds that eligibility-compliance practices even surface among some (but not all) private welfare-to-work contractors. For example, one program created elaborate tools for monitoring attendance at classroom sessions, requiring clients to sit and do nothing if classroom sessions ended early or clients completed assigned tasks.

Sanctions are similarly susceptible to routine or resistant practices. Workers verify compliance with work rules, as they do eligibility, often by completing standardized forms and asking clients to provide documents. Clients typically sign written contracts in which they agree to engage in work activities and to be monitored through reports that track, for example, attendance at work programs and Department of Labor (DOL) appointments to help them look for work. Highly scripted encounters may occur within tight administrative rule structures. As a result, sanctions may be less an evaluative task than a clerical one. For example, sanctions may be applied automatically, as in New York City's welfare bureaucracy, where computer systems are programmed to record sanctions automatically if clients do not appear at a work activity.

Discretion may also play a role in how sanctions are applied. As scholars argue, even the most rule bound of bureaucracies provide opportunities for discretion, both positive and negative (Mashaw 1971; Handler 1986; Brodkin 1997; Fording, Soss, and Schram 2007). Particularly in bureaucracies with limited resources, workers may engage in creaming, or helping those they think will succeed while treating harshly those clients they deem to be troublesome (Lipsky 1980). In the context of sanctions, such practices might mean that workers ignore technical violations, for example, a single missed meeting, if the client is perceived as cooperative. Workers may readily accept such clients' reasons for not complying, demanding only minimal proof. In contrast, sanctions may be applied differently among harder-to-serve clients, typically those with multiple problems and barriers to work. Workers may be more skeptical of their explanations and demand higher levels of proof.

There is some indication that harsh treatment from workers correlates with client disadvantage. Studies show that sanctioned recipients are younger, have more children, and are more likely to have never married than are other recipients (Fein and Lee 1999; Edelhoch et al. 2000; Koralek 2000; Westra and Routley 2000; Mancuso and Lindler 2001; 
Cherlin et al. 2002; Kalil et al. 2002; Hasenfeld et al. 2004; Pavetti et al. 2004). Sanctioned recipients are also more likely than other recipients to have health problems, including alcohol and drug problems, and to experience domestic violence (Mancuso and Lindler 2001; Polit et al. 2001; Cherlin et al. 2002; Kalil et al. 2002; Pavetti et al. 2004). Compared with clients who are not sanctioned, sanctioned clients have less human capital. Research also suggests that sanctioned welfare recipients have lower levels of education, less work experience, and longer periods of time on public assistance (Born et al. 1999; Fein and Lee 1999; Edelhoch et al. 2000; Koralek 2000; Westra and Routley 2000; Mancuso and Lindler 2001; Cherlin et al. 2002; Kalil et al. 2002; Hasenfeld et al. 2004; Pavetti et al. 2004; Wu et al. 2006). Logistical problems, such as securing transportation or child care, are also more frequent among sanctioned recipients than among nonsanctioned ones (Mancuso and Lindler 2001; Cherlin et al. 2002; Kalil et al. 2002; Hasenfeld et al. 2004; Pavetti et al. 2004).

These problems and disadvantages are difficult for workers to resolve because the issues are intractable, but progress is also impeded because workers lack necessary resources and skills (Meyers et al. 1998). Sanctions may create a disincentive for helping the hardest-to-serve clients; workers can more easily issue a sanction than provide a support (Bell 2005). In other words, sanctions support the implicit message that failure stems from a client's unwillingness to work, not from an agency that is not helping.

Alternatively, workers may exercise negative discretion broadly, choosing to apply work rules stringently to most or all clients, with little or no attempt to distinguish the unwilling from the unable or the technical violation from a more serious infraction. Enforcement of technical violations (e.g., client failure to notify the correct worker or agency if a work activity is missed) may substitute for more nuanced assessments. In short, local offices may create the welfare-to-work version of an eligibility-compliance culture. In a recent study (Lens 2006) of the implementation of sanctions in Texas, the author finds that transactions between clients and workers are routinized and mechanical. The findings suggest that workers fail to assess clients' work behaviors fully.

In sum, sanctions may be applied in several different ways. They may be issued in a standardized and highly scripted way that is determined by adherence to predetermined administrative rule structures. This may include applying sanction rules more narrowly than the law requires. Or sanctions may be applied more flexibly; workers may make individualized assessments that include an evaluation of clients' work behaviors over time and place. Finally, workers may also pick and choose among clients, letting cooperative clients who violate work rules off the hook while more readily sanctioning troublesome clients. Understanding workers' choices requires an in-depth analysis of sanction laws, admin- 
istrative rules, and procedures, as well as an examination of how such rules and procedures are applied in individual cases.

\section{Data and Method}

The front lines of the welfare system can be studied in several different ways. A common approach is to view "administration from the inside out" (Brodkin 1997, 6) by observing how workers do their jobs. Another approach is to look from the outside in, interviewing clients about how workers handle their cases. The current study incorporates elements of both approaches, using administrative fair hearing data, generated from within the bureaucracy, to observe worker behavior indirectly. It also relies on data from interviews conducted with clients in a suburban welfare office in Suffolk County, NY. Further, laws, regulations, judicial decisions, and administrative directives are analyzed to examine the legal and administrative structure for imposing sanctions.

As noted above, fair hearings are adversarial administrative proceedings initiated by clients to challenge negative agency actions, including sanctions. A detailed record emerges from the adversarial process, which includes dictates involving the presentation of evidence by the recipient and agency, cross-examination of witnesses, and issuance of a written decision in which the hearing officer summarizes each side's position, reports findings of fact, and applies relevant provisions of the law.

Hearings also provide the researcher with an administrative perspective that differs from the one gained through site observations and from that obtained in retrospective reporting on interviews or surveys of local actors (e.g., agency staff, administrators, and clients). Hearings capture, without any interference from a researcher, the actions of the parties most interested and involved in the transaction. Thus, they reflect what people did, not what they report doing, recall having done, may do, or may not do if under observation. Hearings also provide a rare opportunity to examine the same case from the perspective of both the worker and the client; they provide a he-said, she-said narrative absent from other administrative data.

As legal proceedings, hearings also provide a record, including the types of required documents, of the bureaucracy's administrative processes. Hearings thus reveal the practicalities and details of implementation. Documents are a bureaucracy's central concern, but some bureaucracies are more demanding than others. As Hasenfeld (2000) notes, bureaucracies serving clients of low social status, such as welfare recipients, frequently use harsh service technologies and treat clients with suspicion. Such bureaucracies are likely to disbelieve clients' reasons for not complying with work rules and to require high levels of proof. Scholars note that bureaucracies characterized by eligibility-compliance practices are particularly likely to make excessive and rigid de- 
mands for documents (Brodkin 1986; Kane and Bane 1994). Hearings contain a detailed record of the types and level of proof required. They thus can reveal the service technologies being used and may enable the researcher to recognize the existence of eligibility-compliance and other practices.

In addition, hearings articulate the bureaucracy's view of how the law should be interpreted and applied. Similar to judicial decisions, hearing decisions resolve individual cases by interpreting and applying laws. Thus, like judicial decisions, hearings can enable the researcher to understand particular laws and their application. Because hearings are part of the state welfare bureaucracy, hearing decisions are official pronouncements by the bureaucracy about the bureaucracy. ${ }^{1}$ The decisions, although subject to reversal by courts, are fertile sources for information on how the members of a bureaucracy think and operate at a particular point in time.

One potential limitation of this data source is the fact that cases in the hearing process are not generally representative of New York's welfare cases; few clients appeal. ${ }^{2}$ Researchers demonstrate in other contexts that most people do not complain about official's actions, but the complaints of the few who do typically are representative of the mass of unvoiced complaints (Hyman, Shingler, and Miller 1992). ${ }^{3}$ Even a small number of hearings can serve as an indicator for error in bureaucracy (Altman, Bardo, and Furst 1979). Even if not wholly representative, such complaints highlight areas of contention within the bureaucracy, providing a more complex understanding of frontline interactions. The research value of hearings thus stems not only from the number of cases considered but also from their purpose and function within the bureaucracy.

The fair hearing data are supplemented here with data from interviews of clients who were sanctioned. Half of these participants reportedly did not appeal their sanctions. The perspective of welfare clients is similar to that of consumers providing feedback about a business, and recipients' perspective differs from that represented in administrative accounts. Recipients view the agency from the outside, and they often have a broader and more detailed knowledge of their circumstances than does their overworked and underresourced worker. They can provide a thicker and more detailed description of client-worker interactions than can be captured in administrative records.

Respondents were identified through purposive sampling. ${ }^{4}$ They were referred to me by a nonprofit agency that contracts with the county Department of Social Services (DSS) to assist sanctioned clients in Suffolk County who fail to respond to their sanction by complying with the work rules. In addition, I obtained respondent referrals from several social service agencies in Suffolk County. These organizations include a legal services organization and a nonprofit agency that provides homes for homeless families. Recruitment flyers were also distributed at other 
social service agencies, including nonprofit organizations that run welfare-to-work programs and others that provide crisis intervention services. To increase the proportion of disadvantaged clients in the sample, I recruited respondents from agencies that provide crisis and homeless services. Finally, participants recruited family and friends.

A total of 28 respondents were interviewed in the spring of 2005. Interviews were conducted using a semistructured interview questionnaire. In-depth interviews allow a deep exploration of respondents' sanctioning experience and overall work behavior. The interviews also maximize personal interaction, encouraging familiarity and trust that enhance the validity of the findings (Berg 1998). To ensure respondents' privacy and confidentiality, and to create a more relaxed environment conducive to in-depth interviewing, all but two of the respondents were interviewed in their homes. Two respondents were interviewed in the offices of a nonprofit organization. Interviews lasted a little more than an hour, and respondents were paid $\$ 25$. All but one of the respondents agreed to allow the interview to be tape-recorded. Respondents were asked a series of open-ended questions on their general experiences with the welfare office, prior and present work experience, and experiences and perceptions of work rules and sanctions. Each interview (except the one that was not recorded) was transcribed verbatim.

The interview sample is a mix of short- and long-term clients. Thirteen clients (46 percent of the sample) report that they have been on welfare for 2 years or less, and 15 (53 percent) report receiving assistance for more than 2 years. The interview sample is split by race as follows: 42 percent are black, 46 percent are white, and 14 percent are Hispanic. All but three sample members are female. In general, the interview sample is more educated than the overall welfare population; 48 percent of all welfare recipients in the national sample have a high school diploma or general equivalency diploma (GED), but 54 percent in the interview sample fall into this category (U.S. Department of Health and Human Services n.d.; see table 1 for sample characteristics). ${ }^{5}$ Eleven percent have some postsecondary education.

I also analyzed laws, regulations, administrative directives, and court decisions to understand the legal and administrative structure that governs work rules and sanctions. Judicial cases are included for two reasons. First, court decisions (and especially the appellate court decisions used here) are official and binding sources for how laws should be interpreted and applied. Laws and regulations provide only a partial picture of the law; the judiciary clarifies and interprets broad or vague statutory language. Second, through their review of state administrative hearing decisions, courts determine what errors, if any, administrative agencies have made in the application of laws. ${ }^{6}$ They are thus a useful source for exploring how the bureaucracy operates. 
Table 1

Sample Characteristics

\begin{tabular}{lccrr}
\hline & National* & $\begin{array}{c}\text { Interview } \\
\text { Sample }\end{array}$ & $\begin{array}{c}\text { Short } \\
\text { Term }\end{array}$ & $\begin{array}{r}\text { Long } \\
\text { Term }\end{array}$ \\
\hline Race: & & & & \\
$\quad$ Black & 39 & 42 & 15 & 36 \\
$\quad$ White & 34 & 46 & 69 & 27 \\
$\quad$ Hispanic & 22 & 14 & 15 & 6 \\
Education: & 46 & 36 & 31 & 40 \\
$\quad$ Less than high school diploma or GED & 48 & 54 & 46 & 60 \\
$\quad$ High school diploma or GED & $\ldots$ & 11 & 23 & 0 \\
$\quad$ Postsecondary education & 31 & 35 & 33 & 36 \\
Average age (years) & & & & \\
\hline
\end{tabular}

Note.-GED = general equivalency diploma. Results are presented in percentages unless otherwise specified. All percentages are rounded. All but three sample members are female.

* National characteristics are drawn from the U.S. Department of Health and Human Services (n.d.).

In sum, multiple data sources, including administrative records, client interviews, and official legal and administrative documents are used to explore the application of sanctions. This use of multiple data sources, referred to as triangulation, enhances the reliability of the findings (Padgett 1998).

In total, 127 fair hearing decisions are analyzed. This represents all decisions on work rule violations in Suffolk County in 2002 and 2004. The decisions are examined using content analysis. First, the following data were extracted verbatim from each decision and copied onto a Microsoft Excel spreadsheet: nature of work rule violation, agency's description of violation, client's reason for not complying, and hearing officer's decision and rationale. Cases were grouped according to clients' reasons for noncompliance. The following categories were used: medical or other exemption, lack of notice of appointment date, family obstacles or situational challenges, administrative error, and scheduling conflicts with work or school. This type of "topical survey," or "manifest content analysis," Margarete Sandelowski and Julie Barroso $(2003,911)$ explain, "remain[s] close to those data as given" with little or no interpretation.

Each decision was also subjected to what Sandelowski and Barroso (2003, 912) describe as a "thematic survey." This method draws on empirical and theoretical literature to conduct an analysis that is interpretative and thematic. The analyses "convey an underlying or more latent pattern or repetition discerned in the data" $(2003,912)$ than a topical survey does. Specifically, the decisions were examined for certain organizational forms and practices related to the research questions.

Coding identifies interpretative and thematic patterns in data from the hearing decisions (Miles and Huberman 1994). Provisional codes 
were initially developed by reading through several decisions. Data are coded on two levels. The first level identifies descriptive codes, and the second level identifies thematic ones. Some examples of descriptive codes include "lacking documentation" and "counting the number of required hours worked." Examples of focused thematic codes include "high proof," "negative discretion," and "rigid rule adherence." The high proof code refers to instances in which clients' statements were considered insufficient or dubious and third-party documentary evidence was required. The negative discretion code identifies instances in which determination of noncompliance was based on a narrow interpretation of the rules. The rigid rule adherence code is a more refined example of negative discretion. It is defined as close adherence by workers, administrators, or hearing officers to the work rules, irrespective of a client's overall work effort or the underlying work obstacles he or she faced.

The thematic survey approach was also used to analyze the interview data. This stage of the analysis relied on HyperResearch, a computer software program designed for the analysis of qualitative data. Once again, two levels of codes were used. In the first level, interview transcripts were examined, and a descriptive code was assigned to each line of data. One descriptive code is "making mistakes." It was used if clients described mistakes or misunderstandings related to sanction rules. In the second level, focused coding was used to examine the line codes assigned in level 1, identifying how often each code was used, assessing the importance of each line code, and choosing the codes that best categorized the emerging themes and patterns (Charmaz 2006). "Bureaucratic skepticism" is an example of a focused code that identifies situations in which the client reports a subjective belief or experience that the agency does not believe. Coding was an iterative process, in which the researcher returned to previously coded transcripts to confirm, refute, or modify codes as they developed.

Traditional legal research methods of case law and statutory analysis are employed to analyze laws, regulations, and court decisions on sanctions. Relevant court decisions on sanctions were identified through LexisNexis, a searchable electronic database of court decisions and other legal documents.

\section{Findings}

\section{Legal and Administrative Structure}

In accordance with federal and state law, recipients of public assistance in Suffolk County, NY, are required to engage in work activities. Possible work activities include regular appointments at the New York State DOL, job search activities and job fairs, some educational opportunities and 
training (e.g., GED classes), and the Suffolk Work Experience Program (SWEP). In SWEP, clients who do not find employment are required to work off their grant by performing such tasks as cleaning roads or parks or working at nonprofit and government agencies.

Failure to comply with the work rules results in the imposition of a sanction, which is a pro rata reduction of the violator's portion of the grant (New York Social Services Law, sec. 342 [2]). State law specifies a minimum duration for the penalty period associated with a sanction. The sanction period for the first instance of noncompliance is 1 month (or until the client complies, whichever is longer). The minimum duration of a second sanction is 3 months, and subsequent sanctions last for 6 months (New York Social Services Law, sec. 342 [2]). Suffolk County DSS workers impose the sanction based on information provided by the DOL and other work-related providers (e.g., the various SWEP programs). Workers rely on state laws and regulations in imposing sanctions. The local agency does not supplement these regulations with local administrative directives.

State law permits use of sanctions only if violations are "without good cause" (New York Social Services Law, sec. 342 [2] a). The statute explicitly provides that the good cause standard is met if the parent or caretaker of a child can show that child care was unavailable for a child under age 13 (sec. 342 [1]). Additional good cause exemptions are provided. These include exemptions for clients who experience domestic violence, physical limitations, and mental health limitations (sec. 341 [1] a), but the law allows departmental regulations to identify others (sec. 342 [1]). The law also provides a conciliation process for resolving sanctions and requires that failure to comply must be "willful" (sec. 341 [1] a). ${ }^{7}$

No state regulation further defines willful noncompliance, but the regulations provide additional detail on what constitutes good cause and how to determine it: "In determining whether or not good cause exists, the social services official must consider the facts and circumstances, including information submitted by the individual subject to such requirements. Good cause includes circumstances beyond the individual's control, such as, but not limited to, illness of the member, illness of another household member requiring the presence of the member, a household emergency, or the lack of adequate child care for children who have reached age 6 but are under age 13" (18 New York Codes, Rules, and Regulations, sec. 385.12 [2008]; emphasis added).

Thus, the regulation makes clear that determining good cause necessarily involves discretion; the facts and circumstances of each case must be considered. The regulation also explicitly permits an expansive interpretation by clearly stating that good cause is not limited to the provided examples.

New York State appellate courts have reiterated that the law requires 
that the violation be both without good cause and willful, finding on several occasions that the local agency and the state agency (in its fair hearing decisions) both failed to consider the issue of willfulness (Benjamin v. McGowan, 712 N.Y.S.2d 546 [2000]; Earl v. Turner, 757 N.Y.S.2d 255 [2003]; Dost v. Wing, 792 N.Y.S.2d 105 [2005]). ${ }^{8}$ There are several reasons why the requirement of willfulness makes it difficult for the local agency to impose sanctions. First, the agency must verify whether the client's violation was willful before terminating benefits, and this adds an additional level of inquiry (Benjamin v. McGowan, Earl v. Turner, and Dost $v$. Wing). Second, willfulness and good cause are not equivalent; the willfulness standard expands the range of circumstances in which a sanction may not be imposed. For example, in Dost $v$. Wing, the court found that forgetting an appointment is not a willful act. In that case, the recipient confused the date of the appointment and contacted the agency upon realizing the mistake.

\section{Are Sanction Rules Applied Narrowly?}

The law and regulations place good cause determinations at the heart of the sanction process. Such determinations are necessarily fact specific and discretionary. They involve assessing whether the client's reason for not complying is both true and sufficient. The most common good cause explanation, both in the hearing and interview data, involves family and situational obstacles, such as a client or child's temporary illness, transportation and day care problems, and other family emergencies. These types of obstacles are raised as good cause explanations in 55 percent of the hearing cases ( 70 out of 127) and by 53 percent of the clients interviewed (15 of the 28). Scheduling conflicts with work or school are cited by 20 percent of clients (26 clients) in the fair hearing data and by 17 percent ( 5 clients) in the interview data. Thirteen ( 10 percent) clients from the hearing data and five (18 percent) of the interviewed clients claim that they never received notice of their appointment. Seven fair hearing clients ( 5 percent) and two interviewed clients ( 7 percent) claim that there was a clerical or other error by the agency. Eight fair hearing clients (6 percent) and four interviewed clients ( 7 percent) claim that they were exempt from the work rules. ${ }^{9}$

One way that workers and hearing officers limit the application of good cause exemptions is to refuse to take clients' explanations at face value and to demand additional proof. This routinely occurs in the hearing and interview data. In the hearing data, the hearing officer (and, by extension, the worker) almost always rejects clients' statements and testimony as a source of proof..$^{10}$ Clients won only 14 of 127 hearings, and in only five hearings was a client's testimony, standing alone, sufficient to establish good cause. To be sure, legal proceedings are designed to focus on proof as a means for ascertaining the truth. However, 
the demand for additional proof is not made because the client's testimony was inconsistent or contradicted by other evidence; this occurred in only 17 out of 127 cases. In spite of this, third-party documentation is routinely required, and clients are subjected to stiffer requirements than may be required in the workplace.

Examples of this can be found in both the interview and the hearing data. These situations often involve clients' claims of their own or a child's illness. In the workplace, routine and temporary illnesses (e.g., stomach viruses or the flu) do not necessarily require medical verification, but such verification is routinely required at the welfare center. Verification requirements work against clients because proof is sometimes not available or not practical. An interviewee named Barbara explains. ${ }^{11}$ When she was unable to attend her SWEP assignment because her son had an intestinal virus, the agency refused to accept her statement and pressed her for a physician's note, which she was unable to obtain. Barbara recounts that the agency asked her, "Why didn't you take your baby, run to the doctor? And I said 'cause I didn't have the money to get there. And they was like, 'Well you could have took the bus.' . . . I said no. I said, 'He was sick; he had diarrhea, so I can't go on the bus . . . three buses."

Strict demands for documents also create problems for working clients because such demands clash with the realities of their jobs. Rules stipulate that clients must work a set number of hours per week and require verification of wages. However, clients' work hours often fluctuate, and employers sometimes insist that new employees complete a trial period in which they work a limited schedule with fewer than the mandated number of hours. Employees are sometimes paid in cash, and some employers are unwilling to provide verification of work hours.

Despite this, caseworkers refused to accept clients' statements as employment verification when they worked off the books. Other forms of proof are also rejected because they do not fit the bureaucratic mold. For example, fair hearing data include the story of a client whose employer, a restaurant owner, refused to verify her employment. She unsuccessfully tried to reverse her sanction by providing the hearing officer with letters from two people who saw her working and with case notes from the files of a local legal services attorney, who confirmed that the employer would not verify employment.

Workers also routinely interpret ambiguous or incomplete proof in the least favorable light. In a case from the fair hearing data, a client claimed that she was too ill from her arthritis to attend a work assignment. The progress notes that she produced from her physician at a clinic were deemed insufficient because they only indicate that she needed refills on her prescription and do not contain a detailed synopsis of the flare-up of her illness. In another case from the fair hearing data, a physician's note documented the client's bursitis, diabetic reticulo- 
pathy, and uncontrolled diabetes, but the note was rejected because it did not mention the cold and influenza that caused her to miss her work assignment. Although the client may have misinterpreted or exaggerated her illness, an alternative explanation not considered by workers is that short-staffed and busy medical clinics might not provide thorough documentation.

In hearings, bureaucratic records, or the lack thereof, are routinely accepted over clients' statements, testimony, and even documentary proof. The agency's records are typically viewed as incontrovertible, and little or no room is given to prove bureaucratic error. For example, hearing officers consistently find that clients' calls to workers did not occur if the case record did not mention the call. ${ }^{12}$ In another example from the hearing data, a client produced a time-stamped document faxed to the agency, but the hearing officer ruled that it was not sufficient proof that the agency received the client's fax.

The requirement that the violation be willful is ignored in the fair hearing data and interviews. Confusion and forgetfulness are routinely interpreted as evasive behavior. A client named Katy describes the agency's response when she allegedly confused a DOL appointment with a GED test date: “Can I get rescheduled? Am I gonna get in trouble for this?' They said, 'Yes you are; you are gonna get in trouble.' I'm like, I have all the paperwork here. I can go right now and show I've been looking for work, and I have the dates. I have this one; I have that one; my resume is in here; my resume is in there; it's not like I'm not trying."

The hearing data make an even more explicit case that confusion and forgetfulness are not deemed to be valid reasons for missing appointments. Hearing officers routinely reject such explanations as insufficient. In one illustrative example, the hearing officer acknowledged the credibility of the client's testimony that she forgot the appointment but explained, "It does not constitute a valid reason, as appellant is responsible for keeping track of her appointments." In another case, the client received two letters from the agency close in time. She assumed (incorrectly) that the second letter was to notify her of a change in the appointment. When she appeared on the second date and at the wrong office, she was told that she could not be helped because she missed her first appointment, and she was sanctioned. The hearing officer upheld the sanction, noting that the "confusion over two appointments arose from her failure to safeguard agency correspondence."

Similarly, unintentional acts are construed in negative ways. One illustrative example involves a client who overslept on the day of a physical examination that was required as part of her vocational training to become a certified nursing assistant. Although she completed the physical examination 10 days later, she was sanctioned and not permitted by the agency to complete the course. Upholding the agency's action, 
the hearing officer explained that "the reason for the missed appointment, specifically that the appellant overslept, does not constitute good cause."

Clients' miscommunications with workers and confusion over administrative procedures are also rejected as valid reasons for failing to comply. In one example from the hearing data, a client believed he was not required to report to the DOL for an employment assessment until his physician completed a required medical assessment form. In another example, a client did not report to the assigned work site because she was not approved to receive a voucher for her child's child care; she mistakenly assumed that, because she received child care in the past, a new application was not needed. In both cases, the hearing officers rejected these explanations, noting that the clients had been properly notified of their obligation to report.

In sum, although clients may not have reported honestly to their workers or in hearings, it is also the case that common mistakes, confusion, and unintentional acts are interpreted with suspicion and distrust. Some legal requirements, such as that the violation be willful, are ignored. Other legal provisions, specifically good cause exemptions, are construed narrowly. The latter is accomplished by privileging agency records over clients' accounts, imposing strict standards of proof, routinely requiring third-party documentation, and parsing documents in ways detrimental to the client.

\section{Are Sanctions Applied in a Manner That Subverts Policy Goals?}

The goal of sanctions is to ensure client compliance with work rules. The goal of work rules is to help clients achieve self-sufficiency. However, the data suggest that a narrow focus on rules and procedural compliance undermines these goals. Procedural violations are elevated over substantive outcomes, such that the reporting of work-related events takes on more significance than the event itself. As a consequence, sanctions are imposed even if clients are engaged in ongoing work activities.

The reporting rules are specified in documents provided to all clients. These rules require clients to attend work assignments, DOL appointments, and other activities. In addition, clients are required to notify designated agencies of certain events or problems. For example, clients are required to sign a form in which they agree to contact the DOL if they are terminated from a SWEP assignment. They are also required to notify the DOL in advance if they cannot attend an appointment.

The reporting responsibilities invite workers to avoid complex assessments of clients' willingness to work and instead to ask the much simpler question of whether the proper parties were notified of a missed activity. For example, interview data indicate that several clients abruptly moved to new shelters, some as far as 50 miles away, and were unable 
to attend their SWEP assignments because they lacked transportation. They were sanctioned for not notifying the DOL of the transportation problem. One client explained that the agency moved her to a new shelter, and she therefore assumed (incorrectly) that only her work site supervisor needed to be notified. The agency, however, viewed her failure to notify the DOL as a clear violation of the reporting requirement, and this determination was made despite the fact that the client had a valid reason for not attending.

In another example from the interview data, the agency is reported to have viewed the client's underlying reason for not attending a DOL appointment as less important than whether and to whom she reported it. Jessica, who was pursuing a medical assistant's certificate on her own while attending her SWEP assignment, had a scheduling conflict when her monthly DOL appointment was to take place at the same time as an important test. She chose to take the test, but the DOL had no record that she notified it (a point of contention). She was sanctioned despite her ongoing attendance at the work site and proof from her school of the test date.

Work rules that require a set number of weekly work hours have the anomalous effect of obscuring clients' work efforts. As noted above, the uneven availability of hours that often characterizes low-wage work creates compliance problems for clients. As the fair hearing and interview data reveal, employers may at first employ workers at reduced hours and increase hours over time. Further, home health aide assignments may be canceled, or restaurant hours may fluctuate, leaving clients sometimes short of the hours required. Rather than viewing such circumstances as outside the clients' control, and hence as good cause for not fully complying with work rules, hearing officers adhere strictly to the rules, upholding sanctions if clients fall a few hours short. The work mandate's overall goal, employment, is overlooked or not considered. In one such case, the client was sanctioned when she left her SWEP assignment on a Tuesday to begin a full-time job on the following Sunday. The hearing officer upheld the sanction, noting that the client should have continued in her SWEP assignment until the first day of her new job. That she had secured employment was less relevant than the hours she missed in her transition from SWEP to work.

In sum, a technical, narrow, and often reductive application of the rules obscures clients' work efforts. To be sure, the rules themselves, including rules that require clients to work a certain number of hours per week, direct a certain result. However, rules defining good cause and requiring willfulness permit variation in determining sanctions for individual cases. The choice of rigidity over flexibility when both are possible is characteristic of eligibility-compliance cultures. 


\section{Are Heterogeneous Groups of Clients Sanctioned?}

Another mark of an eligibility-compliance culture is a lack of individualized attention to and differentiation among clients (Kane and Bane 1994; Brodkin 1997). Under such a regime, sanctioned clients would likely be diverse, and different types of clients would be caught up in a bureaucratized sanctioning process that treated most, if not all, clients with suspicion and skepticism.

As the interview data reveal (the fair hearing data do not include demographic data), sanction recipients are a diverse mix of short- and long-term clients who have varying levels of work history and education. Two groups of clients emerge: short-term clients who are job ready and willing to work and long-term clients with multiple disadvantages. Contrary to expectations, both types of clients are sanctioned, and there is no discernible distinction between the two. Ann and Carol exemplify this heterogeneity. They have very different backgrounds, routes to welfare, and motivations toward work, but they share similar sanction histories.

Carol, 38 years old, has a long work history that began when she was 16 and continues through the births of her five children. As she says in describing her return to work just 2 weeks after her youngest child's birth, "I never saw her take her first steps. . . . It was what I had to do to take care of her. To survive, that's what you had to do." She worked as a paralegal for over a decade but lost her job when her employer closed his law office. Because she lacks the required college degree, she could not find employment as a paralegal. Unable to pay the rent, she became homeless. She first applied for welfare at age 37. At the time of the interview, she had been on public assistance for a little over a year. She had a clear plan for leaving welfare; she was pursuing a college degree in adolescent psychology and, to comply with the work rules, was also working as a hostess in a catering company. She was sanctioned several times for failing to attend DOL appointments, which often conflicted with her other obligations.

In contrast, Ann applied for welfare as a teenager and, by age 22, had been on assistance for 4 years. She has three children and is pregnant with her fourth. A high school dropout, she earned her GED and became a certified nursing assistant while on public assistance. Despite earning \$14.50 an hour as a nursing assistant, she resists more than part-time work and cuts her work hours to remain eligible for welfare. Ann repeatedly fails to attend her work assignment, claiming she is stymied by red tape, such as by problems in obtaining the correct form for a child care referral or by miscommunications with the work site.

Carol and Ann are representative of other clients interviewed. One group, composed typically of short-term or transitory welfare users like 


\section{Social Service Review}

Carol, works around the work rules, pursuing educational or work opportunities independently. Interview data suggest that their sense of selfefficacy is high and that they have concrete plans. For example, Jessica, a 33-year-old mother with three children, was on assistance for 1 year and has an extensive work history. She pursues her own plan to increase her earning potential by obtaining a medical assistant's certificate. Because the certificate program does not satisfy the work rules, she also has a SWEP assignment to work at a local social service agency. She made an arrangement with her social service agency supervisor to attend her assignment after school, putting in a day that starts early in the morning and ends at 9:00 at night. She was sanctioned when she missed a routine DOL appointment because it conflicted with a test at school.

Another group of clients includes long-term users who have multiple barriers to work. These clients resist their work assignments, are often in crisis, and find compliance difficult. For example, Gladys, a 28-yearold mother with three children, was on welfare for 6 years and dropped out of school in the tenth grade. She refused a work assignment, explaining, "I don't see myself getting up early in the morning to go down there for all them hours, 35 a week, while everybody gets a paycheck and not me. That doesn't make sense." She was sanctioned repeatedly and claims that various barriers prevent her from complying. She described herself as "used to the sanction."

Despite their obvious differences, these short- and long-term clients have similar sanction histories. Missed appointments at the DOL and the failure to attend SWEP assignment are the most common reasons. The heterogeneity of the clients suggests that workers bureaucratize sanctions, applying them without distinguishing among the types of violations or levels of client work efforts.

\section{Limitations}

This study, like much implementation research, is limited to the sites being studied. This is an especially important limitation in a study of welfare because states have great flexibility in program design and administration. New York is unlike many states in that it imposes only partial sanctions. Workers in the state may apply sanctions differently than do workers with access to the harsher full sanctions. Also, Suffolk is a suburban county; the findings may not be applicable to rural counties with less complex bureaucracies or to larger and more complex bureaucracies located in urban areas.

This study is limited to examining exercises of negative discretion. Positive discretion is difficult to capture. It occurs in cases where workers have a basis to impose a sanction (e.g., a missed work activity) but do not. Such acts do not generate formal notices or appeals and are not likely to be represented in administrative records. Clients are not nec- 
essarily aware of instances in which workers chose not to sanction them. To be sure, the forms of negative discretion described herein, and their application to a heterogeneous group of clients, suggest a particular type of culture often identified with welfare bureaucracies and, hence, are likely not exceptional. Although this study is useful in establishing the forms that negative discretion can take, further studies are needed. Further research may benefit from a different methodological approach that focuses on the use of positive discretion in sanctioning.

The study's findings on the heterogeneity of the sanctioned population are also limited. As noted above, the findings are based solely on the interview data. Although clients were recruited from diverse sources, the sample size is small. This sample differs from those in other studies, noted above, which indicate that the likelihood of receiving a sanction increases with the client's level of disadvantage. Such heterogeneity may be a result of the way sanctions are applied in Suffolk County, and it may be difficult to generalize findings from studies of individual sites. Further research is needed to determine how sanctions affect different subpopulations of welfare recipients.

\section{Discussion and Implications}

The shift in emphasis from cash assistance to work programs raises the potential for fundamental change in the culture of welfare agencies. Kane and Bane (1994) reject an emphasis on eligibility verification and compliance, instead advocating creation of a self-sufficiency culture in which "clients and workers [would engage] in the common tasks of finding work, arranging child care, and so on" (2). However, Mead $(1997,24)$ aptly describes welfare reform as a mix of "help and hassle." It mixes the potential to help clients with the ability to punish them.

New York's statutory and regulatory framework reflects this dichotomy. Although it requires sanctions, it also leaves ample room for individualizing them. The regulatory language allows for an expansive interpretation of good cause provisions, and the statutory requirements that violations be willful give workers considerable leeway. Discretion, though, can be exercised negatively or positively. As Richard Fording and colleagues $(2007,291)$ observe, "Discretion may serve as an entry point for unjust and unequal treatment or, alternatively, may permit the tailoring of more equitable and humane responses."

This study's findings identify the forms that negative discretion can take. Both workers and hearing officers hew to a narrow interpretation of good cause while also making that standard difficult to meet. An ingrained skepticism of clients' explanations leads workers and hearing officers to dismiss clients' proof and to see intentionality where others might recognize forgetfulness or confusion. Sanctions are not individualized but applied broadly. In doing so, workers use bureaucratic short- 
cuts that avoid a full assessment of clients' work efforts. Process is exalted over substance, catching a diverse group of clients in the net of sanctions. In sum, workers replicate the eligibility-compliance style of the past and impose the harsh service technologies typically reserved for low-status clients.

There are several possible explanations for the patterns described here. One lies in the enormity of the task of welfare agencies. Helping clients achieve self-sufficiency is difficult; economic conditions and human capital are equally relevant, if not more so, than welfare center practices (Fang and Keane 2004). The hardships endured by the welfare poor, including high rates of illness and disease, poor housing, inadequate educational systems, and the lack of everyday supports that facilitate work, are well documented (see, e.g., Rank 1994; Edin and Lein 1997; Seccombe 2007). Accordingly, an agency focus on documents and procedural violations, the hallmark of an eligibility-compliance culture, is less complicated than a focus on helping clients obtain self-sufficiency. Rather than helping clients to access support services, or acting after supports fail, sanctions can be used to assign blame and to absolve the worker of any responsibility for a client's failure to achieve self-sufficiency.

On an organizational level, the location of employment services at the DOL instead of the DSS may affect how workers exercise their discretion. As Irene Lurie and Norma Riccucci (2003, 674) explain, "Where responsibility for work activities was transferred to a specialized agency, there was little need for the welfare agency to become, in Moynihan's words, an employment and training program that provided income support. Workers in the welfare agency could continue to focus primarily on cash assistance, food stamps, and Medicaid, paying considerable attention to eligibility and compliance." Sanctions become an eligibility task, performed the same way as other eligibility tasks. Process prevails over substance, and standardization over individual assessments.

Despite its emphasis on support services and organizational flexibility, welfare reform may result in less change than is commonly assumed. As Brodkin (1997) observes, workers' choices about whether to apply rules strictly or generously are shaped by agency incentives and procedures. Welfare reform includes such incentives as work participation rates, mandated weekly work hours, and restricted definitions of work activities. These incentives encourage workers to routinize their work. The work-first approach, which calls for immediate labor market attachment, encourages depersonalized service (Anderson 2001). Virtually all of the clients interviewed are engaged in the same trajectory of work activities, from routine DOL appointments to job search activities, to approved jobs, to SWEP assignments. This similarity invites the standardization and bureaucratization of sanctions. It encourages workers to judge the part, not the whole; a missed DOL meeting is a missed 
meeting, regardless of the other work activities of the client. Likewise, if judged by the single standard of a missed meeting, a short-term, jobready client is no different than a long-term disadvantaged client.

Finally, and perhaps most significantly, workers may be doing what is expected of them, both by the welfare organization and by the policy makers responsible for the bureaucratic structure. As Michael Lipsky (1984) recognized decades ago, there are many ways to disentitle citizens. One way is through legislative schemes that reduce benefits; another is through "bureaucratic disentitlement," or the denial of aid to eligible people through "largely obscure 'bureaucratic' actions and inactions of public authorities" (Lipsky 1984, 3). Lipsky suggests that bureaucratic disentitlement is likely to occur in the absence of legislative change as a way to resolve often hidden societal conflicts concerning the distribution of benefits.

However, disentitlement can also occur in tandem with legislative change and can resolve conflicts within the law. One potential conflict is welfare reform's simultaneous injunctions to help clients with an unprecedented array of supports and also to sanction them. Conflict arises if law and regulations leave unclear which, support or sanction, is appropriate. Likewise, the statutory scheme reinforces and amplifies negative tendencies to view welfare clients homogeneously as unwilling to work, even as the scheme requires individualized and complex judgments of whether work rules violations are willful and without good cause. Thus, although the 1996 welfare reform legislation is aptly described as a punitive and harsh, it also incorporates values of equity and fairness. Courts may uphold provisions designed to ensure fairness (as one did in requiring a New York agency to determine willfulness), but the welfare bureaucracy, both past and present, is highly attuned to the harsh and punitive features of the system. In narrowly interpreting good cause, and even in ignoring the law regarding willfulness, the bureaucracy expands by administrative means welfare reform's harshest provisions.

\section{References}

Altman, Stan, Blayne Bardo, and Dan Furst. 1979. "The Use of State Fair Hearing Data to Monitor Performance of the AFDC Program." Administrative Law Review 31 (4): $463-84$.

Anderson, Steven G. 2001. "Welfare Recipient Views about Caseworker Performance: Lessons for Developing TANF Case Management Practices." Families in Society 82 (2): $165-75$.

Bell, Holly. 2005. "Caseworkers' Assessment of Welfare Reform: Report from the Front Lines." 243-60 in The Impact of Welfare Reform: Balancing Safety Nets and Behavior Modification, edited by Christopher R. Larrison and Michael K. Sullivan. Binghamton, NY: Haworth.

Berg, Bruce. 1998. Qualitative Research Methods for the Social Sciences. 3rd ed. Boston: Allyn \& Bacon.

Born, Catherine E., Pamela J. Caudill, and Melinda L. Cordero. 1999. "Life after Welfare: 
A Look at Sanctioned Families.” Report. University of Maryland, School of Social Work, Baltimore.

Brandwein, Ruth, Jennette Lynch, Roxana Rudulescu, and Robin Seymour. 2000. How Well Is Welfare in Suffolk County? A Study of Current and Former Welfare Recipients. Report of the Welfare-to-Work Subcommittee, Commissioner's Advisory Council. Hauppauge, NY: Suffolk County Department of Social Services.

Brodkin, Evelyn Z. 1986. The False Promise of Administrative Reform: Implementing Quality Control in Welfare. Philadelphia: Temple University Press.

$\rightarrow \longrightarrow$. 1997. "Inside the Welfare Contract: Discretion and Accountability in State Welfare Administration." Social Service Review 71 (1): 1-33.

Charmaz, Kathy. 2006. Constructing Grounded Theory: A Practical Guide through Qualitative Analysis. Thousand Oaks, CA: Sage.

$\rightarrow$ Cherlin, Andrew J., Karen Bogen, James M. Quane, and Linda Burton. 2002. "Operating within the Rules: Welfare Recipients' Experiences with Sanctions and Case Closings." Social Service Review 76 (3): 387-405.

Edelhoch, Marilyn, Qiduan Liu, and Linda Martin. 2000. "The Post-welfare Progress of Sanctioned Clients in South Carolina." Journal of Applied Social Sciences 24 (2): 55-78.

Edin, Kathryn J., and Laura Lein. 1997. Making Ends Meet: How Single Mothers Survive Welfare and Low-Wage Work. New York: Russell Sage.

$\rightarrow$ Fang, Hanming, and Michael P. Keane. 2004. "Assessing the Impact of Welfare Reform on Single Mothers." Brookings Papers on Economic Activity, no. 1:1-95.

Fein, David J., and Wang S. Lee. 1999. "The ABC Evaluation: Carrying and Using the Stick; Financial Sanctions in Delaware's A Better Chance Program." Report to the Delaware Department of Health and Social Services. ABT Associates, Cambridge, MA.

$\rightarrow$ Fording, Richard C., Joe Soss, and Sanford F. Schram. 2007. "Devolution, Discretion, and the Effect of Local Political Values on TANF Sanctioning." Social Service Review 81 (2): $285-316$.

Fraker, Thomas M., Lucia A. Nixon, Jan L. Losby, Carol S. Prindle, and John F. Else. 1997. "Iowa's Limited Benefit Plan." Report to the Iowa Department of Human Services. Mathematica Policy Research, Washington, DC.

Handler, Joel F. 1986. The Conditions of Discretion: Autonomy, Community, Bureaucracy. New York: Russell Sage.

$\rightarrow$ Hasenfeld, Yeheskel. 2000. "Organizational Forms as Moral Practices: The Case of Welfare Departments." Social Service Review 74 (3): 329-51.

$\rightarrow$ Hasenfeld, Yeheskel, Toorjo Ghose, and Kandyce Larson. 2004. "The Logic of Sanctioning Welfare Recipients: An Empirical Assessment.” Social Service Review 78 (2): 304-19.

Haskins, Ron. 2006. "Welfare Reform: Success or Failure?" Policy and Practice 64, no. 1 (March): 10-12.

Hyman, Drew, John Shingler, and Mitchell Miller. 1992. "Consumer Complaints and Public Policy: Validating the 'Tip-of-the-Iceberg' Theory." Sociological Practice 10:97-122.

$\rightarrow$ Kalil, Ariel, Kristin S. Seefeldt, and Hui-chen Wang. 2002. "Sanctions and Material Hardship under TANF." Social Service Review 76 (4): 642-62.

Kane, Thomas J., and Mary Jo Bane. 1994. "The Context for Welfare Reform." 1-27 in Welfare Realities: From Rhetoric to Reform, edited by Mary Jo Bane and David T. Ellwood. Cambridge, MA: Harvard University Press.

Koralek, Robin. 2000. "South Carolina Family Independence Program Process Evaluation: Topical Report; Conciliation and Sanctioning." Report to the South Carolina Department of Social Services (contract no. C00006A-2). Urban Institute, Washington, DC.

$\rightarrow$ Lens, Vicki. 2006. "Examining the Administration of Work Sanctions on the Frontlines of the Welfare System." Social Science Quarterly 87 (3): 573-90.

$\rightarrow$ Lens, Vicki, and Susan Elizabeth Vorsanger. 2005. "Complaining after Claiming: Fair Hearings after Welfare Reform." Social Service Review 79 (3): 430-53.

Lipsky, Michael. 1980. Street-Level Bureaucracy: Dilemmas of the Individual in Public Services. New York: Russell Sage.

$\rightarrow$. 1984. "Bureaucratic Disentitlement in Social Welfare Programs." Social Service Review 58 (1): 3-27.

Lurie, Irene. 2006. At the Front Lines of the Welfare System: A Perspective on the Decline in Caseloads. Albany, NY: Rockefeller Institute. 
$\rightarrow$ Lurie, Irene, and Norma M. Riccucci. 2003. "Changing the 'Culture' of Welfare Offices: From Vision to the Front Lines." Administration and Society 34 (6): 653-77.

Mancuso, David C., and Vanessa L. Lindler. 2001. "Examining the Circumstances of Welfare Leavers and Sanctioned Families in Sonoma County: Final Report." Report to the Sonoma County, CA, Human Services Department and the William and Flora Hewlett Foundation. SPHERE Institute, Burlingame, CA.

Martinson, Karin, and Pamela A. Holcomb. 2002. "Reforming Welfare: Institutional Change and Challenges." Assessing the New Federalism Occasional Paper no. 60. Urban Institute, Washington, DC.

$\rightarrow$ Mashaw, Jerry L. 1971. "Welfare Reform and Local Administration of Aid to Families with Dependent Children in Virginia." Virginia Law Review 57 (5): 818-39.

Mead, Lawrence M. 1997. The New Paternalism: Supervisory Approaches to Poverty. Washington, DC: Brookings Institution.

$\rightarrow$. 2001. "Welfare Reform in Wisconsin: The Local Role." Administration and Society 33 (5): 523-54.

Meyers, Marcia K., and Nara Dillon. 1999. "Institutional Paradoxes: Why Welfare Workers Cannot Reform Welfare." 230-58 in Public Management Reform and Innovation: Research, Theory, and Application, edited by H. George Frederickson and Jocelyn M. Johnston. Tuscaloosa: University of Alabama Press.

$\rightarrow$ Meyers, Marcia K., Bonnie Glaser, and Karin MacDonald. 1998. "On the Front Lines of Welfare Delivery: Are Workers Implementing Policy Reforms?” Journal of Policy Analysis and Management 17 (1): 1-22.

Miles, Matthew B., and A. Michael Huberman. 1994. Qualitative Data Analysis: An Expanded Sourcebook. 2nd ed. Thousand Oaks, CA: Sage.

NYOTDA (New York State Office of Temporary and Disability Assistance), Division of Employment and Transitional Supports. 2005. Non-compliance with Employment Requirements. Directive (OTDA-4357-EL, September 14) by Russell Sykes, division deputy commissioner. General Information System message no. GIS 05TA/DC032. Albany, NY: NYOTDA, Division of Employment and Transitional Supports.

O’Neill, June, and M. Anne Hill. 2003. "Gaining Ground, Moving Up: The Change in the Economic Status of Single Mothers under Welfare Reform." Civic Report no. 35. Manhattan Institute, New York.

Padgett, Deborah K. 1998. Qualitative Methods in Social Work Research: Challenges and Rewards. Thousand Oaks, CA: Sage.

Pavetti, LaDonna, Michelle K. Derr, and Heather Hesketh. 2003. "Review of Sanction Policies and Research Studies: Final Literature Review." Report to the U.S. Department of Health and Human Services (contract no. HHS-100-01-0011). Mathematica Policy Research, Washington, DC.

Pavetti, LaDonna, Michelle K. Derr, Gretchen Kirby, Robert G. Wood, and Melissa A. Clark. 2004. "The Use of TANF Work-Oriented Sanctions in Illinois, New Jersey, and South Carolina: Final Report." Report to the U.S. Department of Health and Human Services (contract no. HHS-100-01-0011). Mathematica Policy Research, Washington, DC.

Polit, Denise F., Andrew S. London, and John M. Martinez. 2001. "The Health of Poor Urban Women: Findings from the Project on Devolution and Urban Change." Report from the Project on Devolution and Social Change. Manpower Demonstration Research Project, New York.

Rank, Mark R. 1994. Living on the Edge: The Realities of Welfare in America. New York: Columbia University Press.

Rector, Robert E., and Sarah E. Youssef. 1999. "The Determinants of Welfare Caseload Decline." Center for Data Analysis Report no. 99-04. Heritage Foundation, Washington, DC.

$\rightarrow$ Riccucci, Norma M., Marcia K. Meyers, Irene Lurie, and Jun Seop Han. 2004. "The Implementation of Welfare Reform Policy: The Role of Public Managers in Front-Line Practices." Public Administration Review 64 (4): 438-48.

$\rightarrow$ Sandelowski, Margarete, and Julie Barroso. 2003. "Classifying the Findings in Qualitative Studies." Qualitative Health Research 13 (7): 905-23.

$\rightarrow$ Sandfort, Jodi R. 2000. "Moving beyond Discretion and Outcomes: Examining Public Management from the Front Lines of the Welfare System." Journal of Public Administration Research and Theory 10 (4): 729-56. 
Seccombe, Karen. 2007. “So You Think I Drive a Cadillac?” Welfare Recipients' Perspectives on the System and Its Reform. Boston: Allyn \& Bacon.

Segal, Elizabeth A., Karen E. Gerdes, and Sue Steiner. 2004. Social Work: An Introduction to the Profession. Belmont, CA: Wadsworth and Brooks Cole.

Suffolk County (New York) Department of Social Services. 2003. Sanction Research Project. Report, May 12. Hauppauge, NY: Suffolk County Department of Social Services.

U.S. Department of Health and Human Services, Office of Family Assistance. n.d. "Characteristics and Financial Circumstances of TANF Recipients: Fiscal Year 2004.” http:// www.acf.hhs.gov/programs/ofa/character/FY2004/indexfy04.htm (accessed March 10, 2008).

U.S. Department of Health and Human Services, Office of Inspector General. 1999. Improving the Effectiveness and Efficiency of Client Sanctions. Report no. OEI-09-98-00290. Washington, DC: U.S. Department of Health and Human Services, Office of the Inspector General.

U.S. Senate, Committee on Finance. 2003. Testimony of Tommy G. Thompson, Secretary, U.S. Department of Health and Human Services, in the hearing Welfare Reform: Building on Success. 108th Cong., 1st sess., March 12.

Westra, Karen L., and John Routley. 2000. Arizona Cash Assistance Exit Study, First Quarter 1998 Cohort: Final Report. Phoenix: Arizona Department of Economic Security, Office of Evaluation.

Wrafter, John. 1984. “QC: Abbreviation for Failure.” Public Welfare 42 (4): 14-21.

Wu, Chi-Fang, Maria Cancian, Daniel R. Meyer, and Geoffrey L. Wallace. 2006. "How Do Welfare Sanctions Work?” Social Work Research 30 (1): 33-50.

\section{Notes}

This study was supported by a grant from the Lois and Samuel Silberman Fund of the New York Community Trust.

1. The Office of Hearings and Appeals, a component of the New York State Office of Temporary and Disability Assistance (NYOTDA), has supervisory responsibility over all hearings in the state. The state is divided by regions, consisting of several counties, and hearing officers are assigned to particular counties within these regions. The NYOTDA state commissioner's designee for each region makes the final decision on individual cases. This decision is based on the hearing officer's findings of fact and law, as well as on the officer's recommendations. Because the hearing system is partially decentralized, hearing outcomes may vary and therefore are more representative of the practices of a particular region or county than of those across the entire state.

2. Appeal rates for financial assistance programs are between 1.1 and 3.5 percent in New York State, outside of New York City (Lens and Vorsanger 2005). Although appeal rates are low outside the city, the rates are higher than the sample size used to assess error rates under quality control (1.5-2 percent according to Wrafter [1984]). In any event, the available administrative data do not permit me to estimate what portion of appeals are related to sanctions, but findings from a recent study (Brandwein et al. 2000) suggest that it may be unusually high. The study, based on surveys of 174 current or former welfare recipients who sought assistance at nonprofit agencies in Suffolk County, finds that almost one-third, or 51 recipients, were sanctioned at some point, and 38 (74 percent) of those sanctioned appealed the sanction by requesting a hearing (Brandwein et al. 2000). Although the study's results are biased by the failure of some recipients to complete the survey (and hence perhaps also the likely failure to appeal), the results still demonstrate an unusually high rate of appeal. In the current study, interviews with the sample of clients also indicate that participants appealed at high rates. Of the 28 clients interviewed, 14 (50 percent) report that they appealed a sanction. The sampling was designed to distinguish clients who appealed from those who did not, and the former were surprisingly easy to identify across the range of referral sources used to recruit participants for interviews.

3. As Hyman and colleagues (1992) explain in their study of the complaint behavior of residential utility customers, if organizational and environmental barriers inhibit complaints, "the universe of problems perceived, voiced, and complained will be successively 
smaller than the universe of problems experienced by consumers" (100). The complaints are more likely to be the tip of the iceberg than to be aberrations.

4. Clients were recruited as part of a larger study that focuses on sanctions. The study examines what motivates clients to use the fair hearing system or impedes them from using it. Thus, purposive sampling is used to identify sanctioned clients who had, or had not, used the fair hearing system.

5. Because sampling was not random, the interview sample may not be representative of the general sanction population in Suffolk County. The only available demographic information on the county's sanction population comes from a study conducted jointly in 2003 by Suffolk County DSS and the Education and Assistance Corporation (EAC), a nonprofit agency that provides services to sanctioned clients under an agreement with DSS (Suffolk County Department of Social Services 2003). The study was based on data from the 489 sanctioned clients who were referred by DSS to EAC for assessment and services in 2002. Clients are referred to EAC if they fail to come into compliance after being sanctioned. Thus, the study does not include all sanctioned clients. It focuses on a subpopulation of sanctioned clients that may or may not be more disadvantaged than the overall sanctioned population. Although sanctions may not compel some clients to comply because they have other sources of income and are willing to accept a grant reduction, others may be unable to comply because of multiple barriers. In any event, the sample in this study differs from the sample in the sanction study. The primary differences relate to the level of education. The current study sample reports higher education levels than those reported by the Suffolk County study population (Suffolk County Department of Social Services 2003). In the current study, 54 percent report that they have a high school diploma or GED; the rate was 34 percent in the Suffolk County study. Overall, 42 percent of the current study's sample is black, 46 percent is white, and 14 percent is Hispanic. In the Suffolk County study, 50 percent were black, 28 percent were white, 17 percent were Hispanic, and 5 percent identified themselves as members of some other group. The average age of the current sample is 35 ; it was 32 in the Suffolk County study.

6. Administrative hearing decisions are reviewable by the state courts through a proceeding filed under article 78 of the New York Civil Practice Law and Rules. The standard of review is whether the decision is based on substantial evidence or is arbitrary, capricious, or an abuse of discretion (New York Civil Practice Law and Rules, sec. 7803).

7. The purpose of conciliations is to provide clients with an additional opportunity to present their reasons for noncompliance before their grant is reduced. The local agency is required to offer conciliations, but participation is voluntary and does not affect a client's right to request a fair hearing.

8. That the failure to consider the issue of willfulness, despite a statutory mandate, was widespread seems to be indicated by a General Information System (GIS) notice sent in September, 2005, by the NYOTDA (2005) to all welfare districts. It advised districts that, in accordance with the court decisions in Earl $v$. Turner and Dost $v$. Wing, they must revise their sanction procedures to include a determination of willfulness. The GIS notice emphasized that such determinations must be made on a case-by-case basis and should include "identifying a pattern of the recipient's failure to take reasonable steps to address issues within the recipient's control that may prevent the recipient from complying with employment requirements" (NYOTDA 2005, 1).

9. In the results presented for noncompliance among the interviewed clients, the sum of the percentages exceeds 100 because several clients had multiple sanctions and therefore provided multiple reasons for noncompliance.

10. The evidence submitted at the hearing is sometimes, but not always, different than the evidence submitted to the agency when the sanction is first imposed. The agency has the option of withdrawing the sanction upon examining the client's evidence at the hearing. No statistics are available on the frequency with which the agency exercises this option in sanction cases, but the agency withdraws its notice in about one-third of all hearing cases in Suffolk County. Both through the initial imposition of the sanction and by not withdrawing, the agency rejects the client's proof. Thus, for the purpose of this analysis, the hearing officer's and the agency's standards of proof are viewed as interchangeable if the sanction is upheld.

11. To protect the confidentiality of the participants, all names in this article are pseudonyms.

12. The hearing officer found otherwise in only one observed case. In that case, the 
Social Service Review

recipient submitted personal telephone records indicating that she placed a call to the DOL and further evidence that not all phone calls from clients to the DOL were logged in case records. 